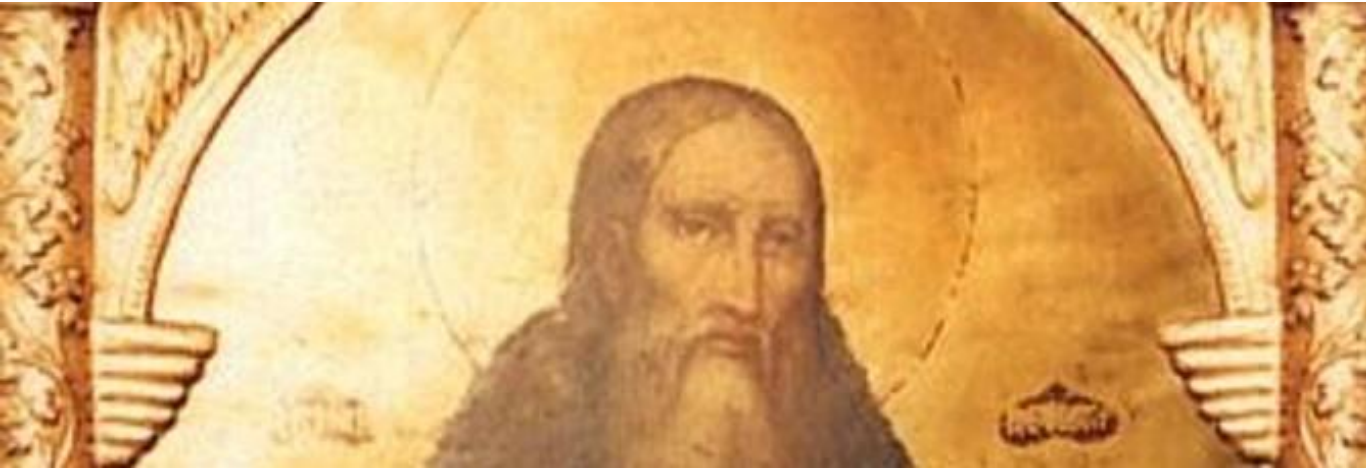

\section{La Cristiandad bizantina en la Rus de Kiev (c. 862-c. 1230), pilar religioso ruso}

\author{
The Bizantyne Christendom in Kievan Rus (c. 862-c. 1230), Russian Religious \\ pillar
}

\section{Resumen}

Este artículo analiza el papel que la Iglesia Cristiana bizantina tuvo en la formación del primer estado de los eslavos del este llamado por la historiografía sobre el tema la Rus de Kiev. En este periodo, al mismo tiempo que se formó el estado, se sumaron costumbres, prácticas y tradiciones que, paulatinamente, ayudaron a construir la identidad rusa. En este proceso, la adopción del cristianismo bizantino desempeñó un papel determinante. Esta religión implicó que los rusos practicaran una fe enmarcada en una iglesia institucionalizada la cual les brindó características políticas, sociales y culturales que han sido fundamentales en su etnogénesis.

\section{Palabras clave}

Estado, Iglesia cristiana bizantina, religión, etnogénesis, identidad

\begin{abstract}
In this paper I analyze the roll the Byzantine Christian Church played in the emergence of the first East Slavs' state which the historiography denominates the Kievan Rus. In this period, at the same time the state was created, the people adopted habits, practices, and traditions, which slowly, contributed to the construction of the Russian identity. In this process, Byzantine Christianity was a decisive contributor. This religion, with an institutionalized church, gave Russians political, social, and cultural features which have been fundamental in their ethnogenesis.
\end{abstract}

\section{Keywords}

State, Byzantine Christian Church, religion, ethnogenesis, identity
MARTHA ORTEGASOTO

Universidad Autónoma Metropolitana,

México

Doctora de Humanidades- Historia por la Universidad Autónoma Metropolitana Unidad Iztapalapa. Profesora-investigadora en la misma Universidad. Ha estudiado la colonización de Alta California, América Rusa, Historia de Rusia, de los Balcanes y el norte del Pacífico. También realiza investigaciones en el campo de la Historia de la Cienciay la Tecnología en los campos de la energía nuclear y la extracción del uranio. Asimismo, ha participado en el rescate de archivos bajo custodia de laUAM.

\title{
ORC
}

Recepción de artículo: 31-8-2020

Aceptación del artículo: 30-4-2021 


\section{PRESENTACION}

Uno de los fenómenos sociales que brinda una gran cohesión a las comunidades humanas tengan o no una organización estatal, es la religión.

La religión, entendida en un sentido amplio, representa el meollo de la cultura de cualquier pueblo o civilización. Es la fuente no sólo delos valores morales e intelectuales, sino también de ideas y conceptos que definen y legitiman la estructura social y hasta el orden político y económico. A su vez, la religión de cualquier puebloo civilización está impregnada de estas estructuras sociales, políticas y económicas ${ }^{1}$.

Para mostrar con mayor claridad la importancia de la Iglesia bizantina para la transformación de un segmento de los eslavos del este en rusos, es decir su etnogénesis, expondré cómo la cristiandad bizantina fue un factor aglutinante cuando el poder de Kiev decayó y los principados de la Rus que surgieron de su disgregación mantuvieron una cultura común apoyada en ella. En este artículo se entiende por etnogénesis la construcción histórica de un pueblo². A partir de diversas comunidades ocurrió un proceso de fusión que, paulatinamente, originó un conglomerado que se distinguió a sí mismo de otro. En este caso, comunidades eslavas del este se transformaron, en virtud de sus experiencias históricas compartidas, en rusos. Asimismo, se mostrará cómola Iglesiabizantina de la Rus sobrevivióa la invasión de los mongoles y logró que los principados sometidos conservaran una religión diferente a la de sus conquistadores. Este precedente se ha conservado en la memoria cultural ${ }^{3}$, del pueblo ruso hasta la actualidad, a pesar de los avatares padecidos a lo largo de su historia y mantiene su importancia como pilar en la conceptualización de lo ruso. La memoria cultural de una comunidad consiste en compartir experiencias del pasado, prácticas sociales tales como una cosmovisión común, relaciones sociales regidas por códigos comunes, así como rituales. Se concibe que estas han sido compartidas en el pasado, se comparten en el presentey se proyectan hacia el futuroya que la comunidad adquiere el compromiso de respetarlas. Estas prácticas comunes constituyen elementos fundamentales de la identidad colectiva ${ }^{4}$.

Elartículonoes decarácterteológico, portanto, noabordaréladiscusión acerca de qué es la fe y por qué los seres humanos la practican de manera personal y comunitariamente. Tampoco discutiré acerca de la existencia de la divinidad. Mi análisis parte de la premisa de que la fe existe y la mayoría de los hombres y mujeres, a lo largo de la historia, la han tenido. Tan solo puedo afirmar, como historiadora, que la fe se ha manifestado desde tiempos inmemoriales y que lo sagrado y la divinidad han estado presentes a lo largo de la historia humana. De acuerdo con uno de los más connotados historiadores de las creencias religiosas:

En una palabra: lo "sagrado" es un elemento de la estructura de la conciencia, no un estadio de la historia de esa conciencia. En los niveles más arcaicos de la cultura el vivir del ser humano es ya de por sí un acto religioso, pues tomar el alimento, ejercer la sexualidad y trabajar son actos que poseen un valor sacramental. Dicho de otro modo: ser -o más bien hacerse- hombresignifica ser "religioso".

La fe se tiene o no se tiene y, de acuerdo con el cristianismo bizantino es un don concedido por la divinidad. Tiene fe aquel que es acreedor de la gracia divina, pero para obtenerla es necesario tener fe y cumplir con los preceptos religiosos. El dogma se conoce, es posible discutir sobre él, pero se acata. El cristianismo paulatinamente se institucionalizó adquiriendo una estructura ministerial y pastoral y se difundió entre pueblos que eran considerados paganos por los cristianos, este artículo se refiere específicamente a cómo se introdujo el cristianismo bizantino, yainstitucionalizado, en la Rus de Kievy cómo su inmediata adopción, tanto en términos espirituales como institucionales, en ese estado contribuyó a consolidarlo. La adquisición de esta religión cumplió la función, siguiendo a Hans Mol, ${ }^{6}$ de sacralizar las costumbres y prácticas de los rus y originar la etnogénesis de la identidad rusa que actualmente todavía existe.

Las fuentes que se refieren a la práctica religiosa en ese periodo son escasas, pero existe una bibliografía abundante sobre la iglesia institucionalizada puesto que, como ya apuntamos, ha sido una pieza clave en la construcción de lo ruso.

\section{ANTECEDENTES}

Desde que el cristianismo surgió, para formar parte de la comunidad era necesario el bautismo. En un principio, sólo lo recibían aquellos que habían sido adoctrinados en la fe y estaban dispuestos a abrazarla. Por ello, era indispensable la labor pastoral o de evangelización. En torno al sacramento de la eucaristía giran la teología y la liturgia del cristianismo ya que representa la Cena con el Dios universal y reitera la fe en la salvación. La eucaristía estaba precedida de la lectura de las Sagradas Escrituras y de la predicación. En principio, únicamente el obispo, es decir el jefe de la comunidad, tenía la facultad de bendecir el pan que se compartía entre todos los fieles. A medida que el cristianismo ganó más adeptos, los sacerdotes también bendijeron el pan. Para obtener el perdón de los pecados, el creyente confesaba sus faltas al obispo y cumplía con la penitencia que éste le imponía ${ }^{7}$. Éstos son los ritos más importantes para los cristianos porque con ellos se integran a una comunidad de fe en un Dios único que redime a la humanidad de sus pecados y les permite acceder al Reino de los Cielos después de la muerte para disfrutar de la paz eterna en la gloria de Dios. Es indispensable enfatizar que, aunque el cristianismo tiene influencia de la filosofía grecolatina-lo que dio lugar al desarrollo de la teología-es una religión en tanto que acepta la existencia de Dios y de su revelación a los seres humanos.

Lorenzen y Preciado 2003, p. 11.

Pohl 1998.

Assmann 1995, pp.125-133.

Assmann 1995, pp.132-133.

Eliade 1999, p. 17.

Mol 1976.

Descripción basada en Historia Universal 7. El origen de las grandes religiones 2005, pp. 300-315. 
Desde el siglo $\mathrm{II}^{8}$, se desarrollaron la liturgia y los preceptos derivados de la tradición para practicar la fe, pero cada iglesia tenía como guía y jefe a su propio obispo quien imponía la ortodoxia en su comunidad. Le ayudaban en su ministerio diáconos, presbíteros y laicos, de manera que fue creándose una estructura pastoral y episcopal jerarquizada. Ya que cada obispo interpretaba las sagradas escrituras no existía una interpretación unificada del ministerio de Jesús ni tampoco de su concepción como Dios encarnado o como enviado de Dios. Ante la diversidad, hubo quienes procuraron mantener la unidad de la iglesia cristiana y poco a poco establecieron el canon del Nuevo Testamento y su continuidad con el Antiguo Testamento.

El cristianismo se consolidó como una religión institucionalizada bajo la protección del imperio romano cuando Constantino el Grande promulgó el Edicto de Milán en 313 gracias al cual fue tolerada. Si bien la conversión del emperador, en 324, no hizo del cristianismo la religión oficial del imperio implicó el reconocimiento de que era una práctica imposible de desarraigar y a partir de entonces Constantino gobernó como cristiano. De acuerdo con los postulados de Eusebio de Cesárea ${ }^{9}$, asesor del emperador; el reino celestial requería de un dirigente terrenal que guiara a los creyentes a la salvación, esta unidad la encarnaba Constantino. Para que la iglesia le brindara un fuerte soporte político, el emperador convocó al Concilio de Nicea al año siguiente y con este acto se erigió como el administrador del poder divino en la tierra. La dirección de la iglesia por el Estado es una característica que ha conservado la iglesia cristiana bizantina. Por ello desde la conversión de los rus de Kiev, los gobernantes han sido la cabeza de la Iglesia y la jerarquía eclesiástica se ha destacado por someterse y defender al Estado. El papel del clero en la época de la Tribulaciones ${ }^{10}$ en el imperio ruso es un ejemplo de esta defensa, no analizaremos este proceso porque el periodo rebasa la temporalidad de este artículo.

Para Constantino el Grande era necesario establecer una interpretación unificada acerca de la naturaleza de Cristo, de las tareas de los obispos y del papel de la jerarquía episcopal pues solo así podría convertirse en una religión susceptible de ser adoptada por sus súbditos sin diferencias en las creencias ni en las prácticas. Bajo su dirección, los obispos reunidos en el Concilio de Nicea fijaron el canon, estableciendo los dogmas fundamentales -como el del misterio de la Trinidad-y las escrituras que se considerarían válidas tachando a otros manuscritos como apócrifos. Aquellos que siendo cristianos disintieran de esta interpretación oficial fueron considerados como herejes. Además, Constantino construyó una ciudad santa a la que mudó la capital del imperio romano. Constantinopla fue consagrada en 330 y se convirtió para muchos creyentes en una segunda Roma.

Fue en 380 cuando el emperador Teodosio con el Edicto de Tesalónica, declaró al cristianismo como la religión oficial transformando al imperio en romano cristiano en 391. Diez años atrás, el emperador había convocado al Concilio de Constantinopla de carácter ecuménico en el que se ratificó la profesión de fe de Nicea ${ }^{11}$. A pesar de este esfuerzo unificador, el cristianismo oriental y el occidental tenían divergencias en la interpretación de los dogmas, de hecho, en principio fueron reconocidos tres patriarcados-Alejandría, Antioquia y Roma- de los que dependían los obispos nombrados en las diócesis. Mas tarde, a ellos se sumaron Constantinopla y Jerusalén según los acuerdos del Concilio de Calcedonia realizado en 451. Esta estructura era básicamente administrativa porque en cuestiones teológicas decidía la Asamblea de obispos agrupados en el Sínodo o Concilio convocados por el emperador. Cada patriarcado tuvo a sus teólogos y por ello la interpretación de las Sagradas Escrituras no fue homogénea pese a los esfuerzos de los emperadores. Asimismo, se establecieron diferencias en las prácticas litúrgicas y en la relación que tenían con el poder político secular. En cualquier caso, la adopción de cristianismo como la religión del imperio romano le brindó a la iglesia cristiana la capacidad de fortalecer su estructura episcopal y dispuso de recursos económicos otorgados por el Estado para sostenerse ${ }^{12}$. A pesar de las diferencias teológicas y litúrgicas el cristianismo exigía de sus practicantes la sumisión a Dios y su revelación y en las iglesias institucionalizadas la guía de sus representantes en la tierra. En última instancia cuando hablamos de religión, de memoria cultural o de sacralización de la identidad, estamos hablando de ideología. Al referirnos a una iglesia institucionalizada aludimos a un aparato ideológico del Estado, condición que obtuvo la iglesia cristiana episcopal al integrase en la estructura de poder del imperio romano. Ya Louis Althusser señalaba en 1968: "Llamamos aparatos ideológicos del estado a cierto número de realidades que se presentan al observador bajo la forma de instituciones precisas y especializadas"13. Entre ellos especificó a las iglesias.

A la muerte de Teodosio, el imperio romano se dividió en Imperio Romano deOccidente con capital en Rávena e Imperio Romano de Oriente con capitalen Constantinopla. Esta división política afectó a laiglesia pues el patriarca de Constantinopla, sujeto al poder delemperador, Ilevóala cristiandad oriental por un rumbo diferente al que tomó el obispo de Roma quien en la práctica dirigió a la cristiandad occidental sin acatar estrictamente las directrices imperiales.

\section{LA IGLESIA BIZANTINA, ORIENTAL O GRIEGA}

En la iglesia oriental las diócesis y las provincias eclesiásticas quedaron bajoelcontroldel patriarca,encargadodevelarporqueensujurisdicción no hubiera lugar para los herejes. Los patriarcados se fundaron en ciudades con una actividad política importante. Tal vez debido a la subordinación de los patriarcas al emperador-concebido como un gobernante sacralizado- ninguno de ellos adquirió primacía sobre el resto ${ }^{14}$. Para efectos de nuestro análisis nos concentraremos en el patriarcado de Constantinopla pues fue esta iglesia la que convirtió a la mayoría de los eslavos al cristianismo. 
El imperio Romano de Oriente, más tarde conocido también como imperio bizantino, se inclinó cada vez más hacia la tradición griega. En 610 Heraclio tomó las riendas del imperio en ese momento amenazado por el imperio sasánida y por el reino de los ávaros. Entretanto, los asentamientos eslavos en los Balcanes eran cada vez más numerosos, a tal punto que el territorio parecía perdido para el imperio. Tras largas batallas, por fin, en 630, Heraclio entró vencedor a Constantinopla, el imperio sasánida había quedado destruido y el reino de los ávaros fue avasallado por los búlgaros, los croatas y los serbios, instigados porel propio emperador. La situación de crisis que el imperio bizantino superó llevó a Heraclio a reformarlo. Conservando el poder centralizado, dividió el territorio en provincias al frente de las cuales había un estratega, el jefe administrativo pronto desapareció, esto significó la militarización delimperio. Paraunificarasus súbditos hizo del griegoelidioma oficial y tras vencer a los sasánidas se proclamó basileus e hizo a un lado el título de césar. Fue él quien se enfrentó por primera vez a los árabes musulmanes que iniciaban su expansión ${ }^{15}$. Estas reformas, así como el rechazo al islam impactaron a la iglesia cristiana oriental, elementos que poco después se difundieron entre los eslavos convertidos al cristianismo bizantino. Un proceso importante para la difusión del cristianismo oriental entre esos pueblos consistió en que desde el siglo VII las relaciones del imperio eran más estrechas, aunque no necesariamente pacíficas, con los estados y pueblos asiáticos y del este de Europa. Así, la iglesia griega o bizantina se mantenía como la institución religiosa más importante política y culturalmente en el Mediterráneo oriental, de hecho, tras intentar en vano expulsar a los eslavos de los Balcanes había llegado el momento de cristianizarlos para evitar que cayeran bajo la influencia de la iglesia latina o, peor aún, de los musulmanes.

En la segunda mitad del siglo IX inició el proceso de cristianización del reino de Bulgaria ${ }^{16}$. Esta experiencia sentó las bases para continuar con la conversión de los eslavos del sur y los eslavos del este. El territorio al sur del río Danubio formaba parte del imperio bizantino pero los eslavos que se asentaron ahí desde el siglo VIluchaban en su contray en varias ocasiones sitiaron Constantinopla, aunque nunca la tomaron. Los griegos que residían en esa región del imperio debían convivir con estos pueblos paganos y por ello era indispensable integrarlos a la esfera cultural bizantina. Por tanto, al mismo tiempo que los misioneros bizantinos trabajaban en la conversión de los búlgaros iniciaron su labor en el reino de los moravos. En 865 el zar Boris, al frente del reino búlgaro, adoptó el cristianismo bizantino, es decir, casi doscientos años después, de la labormisionera de Ciriloy Metodio ${ }^{17}$. Ellos adaptaronel alfabeto griego al búlgaro de manera que los idiomas eslavos pudieron escribirse gracias a la evangelización. Por otra parte, en el siglo IX fue reconstruido el antiguo reino moravo, aunque su existencia fue breve pues los germanosy los magiares sealiaron para destruirlo ${ }^{18}$, también sentó un precedente entre los eslavos del sur y orientales tanto para la conversión al cristianismo bizantino como para la aspiración de fundar reinos soberanos. La traducción de los textos sagrados al eslavo antiguo inició por tanto en Bulgaria y Moravia así comola participación de la iglesia en la administración de estos reinos y su incorporación a la ecúmene cristiana, elementos que más tarde fueron introducidos entre los eslavos del este.

En el siglo $X$ el cristianismo bizantino fue adoptado por los eslavos del este cuando se instauraba el primer estado en la región: la Rus de Kiev considerado por la historiografía rusa como el antecedente histórico del principado de Moscovia cuyo ulterior desarrollo decantó en el imperio ruso.

En resumen, para los eslavos del sur y del este la adopción del cristianismo bizantino significó integrarse a la cristiandad medieval y recibir la influencia de la cultura griega bizantina que contribuyó a enriquecer la suya propia ya que los eslavos vivieron un proceso de interculturalidad cuyos resultados pueden observarse hasta el presente. Este vínculo transmitió la concepción del gobernante como intérprete de la voluntad divina a su pueblo y permitió la creación de una burocracia al estilo bizantino para administrar sus reinos. Por otra parte, la Iglesia bizantina facilitó, a través de los patriarcados, que se desarrollaran iglesias nacionales y que las lenguas eslavas pudieran escribirse puesto que la Iglesia oriental no tenía una lengua sagrada, de manera que los pueblos convertidos fueron adoctrinados en su propio idioma, lo que facilitó que lo conservaran ${ }^{19}$. Para comprender mejor la labor de la Iglesia bizantina entre los eslavos analizaremos los primeros siglos de esta entre los eslavos del este.

\section{LA LLEGADA DE LA IGLESIA BIZANTINA A KIEV}

La primera noticia sobre las posibilidades de la conversión de los rus de Kiev al cristianismo la tenemos durante la regencia de Olga. Ella tomó las riendas del principado debido a que su hijo Svyatoslav todavía era pequeño. Realizó algunas reformas y, según la tradición, fue bautizada en 957 cuando visitó la corte del imperio bizantino. Sin embargo, su hijo no se mostró dispuesto a adoptar el cristianismo de manera que no se impuso en el principado de Kiev ${ }^{20}$.

Cuando en 980 el príncipe Vladimir, nieto de Olga, tomó el poder en Kiev, era pagano y tenía muchas concubinas. Al mismo tiempo se percató de que la administración del principado requería de instituciones para controlar a sus súbditos y a las riquezas que se producían en el territorio bajosudominio. Además, eranecesario cohesionaralos pueblos bajo su poder con algo más que la conquista. La Iglesia bizantina podía proporcionar algunos de estos recursos: era una institución capaz de contribuir a unificaralos habitantes entanto todosprofesaranlamisma fe, de esta forma podría proyectarse hacia el pasado un origen común que los diferenciara de los paganos que los rodeaban. Además, la iglesia contaba con hombres ilustrados que practicaban la escritura mediante la cual se hacían registros de todo tipo, incluso históricos. En el caso de la Iglesia bizantina se añadía la ventaja de que había desarrollado una escritura específica para el eslavo antiguo, idioma que hablaban la mayoría de los habitantes de suprincipado.

Ibidem, pp. 256-263; Serrano del Pozo 2018, pp. 87-113.

Ortega, 2003, pp.122-123, 126-129; Ortega 2004, pp. 156-159.

Talbot Rice 1989, pp. 217-218.

Ibidem, p. 221.

Hussey 1989, pp. 176-210. 
Pero la decisión no fue tomada a la ligera, según La Primera Crónica Rusa ${ }^{21}$, Vladimirrecibiótantolas propuestas de los búlgaros del Volga, quienes eran musulmanes, de los cristianos romanos del imperio germano romano y hasta de losjudíos del janato jázaro-ubicadoentreelnoreste del Mar Negro, el noreste del Mar Caspio y el Cáucaso- para que se convirtiera a sus respectivas religiones.

Vladimir reunió a sus boyardos, es decir a la alta nobleza del principado todos ellos terratenientes, y les tomó su parecer. Éstos le aconsejaron que enviara emisarios a observar las distintas prácticas religiosas. Entre los boyardos y el pueblo eligieron diez emisarios para visitar el jaganato de los búlgaros, el imperio germánico y el bizantino, a su regreso los enviados presentaron sus informes ante el príncipe, los boyardosylos ancianos, estos últimos representantes de las comunidades campesinas. Los boyardos opinaron que se optara por la religión de Bizancio. Vladimir les preguntó si estarían dispuestos a bautizarse, ellos contestaron que la decisión la tenía Vladimir. El príncipe decidió convertirse al cristianismo bizantino ${ }^{22}$. Es preciso señalar que en este momento el príncipe no ejercía un poder centralizado, como el emperador bizantino, sino que negociaba con la nobleza y con loscampesinos.

Pasó un año sin que los emperadores de Bizancio atendieran el deseo de los rus de bautizarse. Vladimir se dirigió a tomar la ciudad de Quersoneso, a orillas del Mar Negro, la cual estaba en manos de los bizantinos. Una vez que logró someterla, envió una embajada a los emperadores Basilio II y Constantino VIII, miembros de la dinastía macedónica, cuya misión consistió en solicitara su hermana en matrimonio, denoconcedérsela atacaría Constantinopla. Los emperadores accedieron y el príncipe de Kiev se casó con Ana Porfirogeneta. El matrimonio implicó la conversión de Vladimir al cristianismo bizantino en 988 y con él todo su pueblo pues los plebeyos debían profesar la religión de sus príncipes.

Apartirdeesemomentolainfluenciadelaculturagriegaydelcristianismo bizantino fue determinante en lasociedad y en el ejercicio del poderen Kiev y toda la Rus. De hecho, pronto el metropolitano de Kiev, quien dependía del patriarca de Constantinopla, obtuvo un gran poder. Vladimir y sus sucesores reconocieron, además, el emperador bizantino como la cabeza de la ecúmene de la cristiandad y no cuestionaron su poder. Sin embargo, es preciso subrayar que, a pesar de esta subordinación aparente, los príncipes de Kiev siempre conservaron su soberanía, es decir, no se integraron al imperio ni territorial nipolíticamente. La razón principal de esta independencia radicó en que el territorio ocupado por los rus no había formado parte del imperio romano. La conversión implicó para Bizancio cumplir con la responsabilidad del emperador de convertir a los paganos al cristianismo, pero en este caso no había antecedente alguno que justificara imponer su dominio político sobre ese estado. Tal vez por ello los rus y más tarde los rusos fueron los mejores aliados del imperio ${ }^{23}$. Poco a poco se fue construyendo una memoria cultural que contribuyó a formar la etnogénesis de los rusos al reconocerse como diferentes a otros pueblos eslavos y desdeluego a sus vecinos musulmanes y paganos.

No está por demás recordar que los ritos y el trabajo de los clérigos se realizaron en el idioma eslavo antiguo. De acuerdo con La Primera Crónica, Vladimir obligó a los hijos de las familias de mayor rango social a instruirse en la nueva religión y a que se habilitaran en la escritura y la lectura. Ya que la iglesia contribuyó a crear las instituciones y a formar los cuadros de administradores y embajadores que poco a poco reforzaron el poder del príncipe, los religiosos ocuparon el lugar de consejeros. El influjo político del clero bizantino fue inmediato, la adopción misma del cristianismo bizantino fue un acto político que alineó al naciente Estado con aquellos que tenían la misma religión. Vladimir destruyó los templos paganos y mandó construir la Iglesia de los Diezmos dedicada a la virgen, para decorarla hizollevar artesanos del imperio bizantino. Al parecer, el príncipe concedió a la iglesia tierras, el cobro del diezmo y las ganancias que se obtuvieran de la cría de ganado y el comercio; así los templos cristianos pronto se convirtieron en centros de intercambio de bienes y también de ideología. Más tarde, Vladimir fue canonizado por la Iglesia bizantina ${ }^{24}$.

Su sucesor, el príncipe Yaroslav, promovió, según la tradición, la traducción de obras griegas al eslavo. Sin embargo, los estudios de filología más recientes muestran que la mayoría de las fuentes de origengriego traducidas al eslavo antiguo hablado por los rus fueron a su vez una traducción de los textos escritos en búlgaro, lo que indica que la élite letradadelaRus, incluyendoalos clérigos, no sabíangriego. Además, si biengran parte de las sagradas escrituras y la hagiografíallegaron a Kiev, no ocurrió lo mismo con los tratados teológicos ya que el eslavo antiguo tenía un lenguaje limitado para traducir este tipo de trabajos, pero la nueva fe fue aceptada a pesar de ello ${ }^{25}$.

Al parecer, Yaroslav el Sabio llegó a un acuerdo con elemperador bizantino en 1037 respecto a los prelados que regirían a la iglesia de Kiev. Quedó establecido que el patriarca de Constantinopla nombraría al metropolitano de Kiev pero el príncipe designaría a los obispos. Ya en aquel momento existían diez obispados en Kiev. Los obispos fueron originarios del principado mientras que los patriarcas eran griegos con la única excepción de Hilarión y Clemente. Yarosalv mandó construir templos al estilo bizantino tanto en Kiev como en Novgorod, la otra ciudad más importante de la Rus y centro comercial en el norte, entre ellos la catedral de Santa Sofía imitando la que se encontraba en Constantinopla. También fundó los monasterios de San Jorge y Santa Irene. Considero que tanto la jerarquía eclesiástica local como los templos se convirtieron en símbolos sagrados para los rus y sus descendientes contribuyendo a nutrir su memoria cultural.

Sobre los monasterios en el cristianismo oriental, cabe hacer algunas aclaraciones. La presencia del cristianismo en las áreas rurales produjo una crítica hacia la iglesia episcopal que residía en las ciudades. Así nació desde el siglo IV un movimiento ascético en Egipto que cuestionaba a la jerarquía eclesiástica. En un primer momento los ascetas vivían aislados, pero pronto aparecieron los ascetas cenobitas. El monacato se difundió en Egipto, Siria y Palestina. El objetivo de los monjes era vivir apartados de la sociedad dedicados a la oración y la meditación. La población rural percibió a los ascetas cenobitas como hombres santos y se les consideró como el ejemplo de vida cristiana ${ }^{26}$. Basilio el Grande

The Russian Primary Chronicle. Laurentian Text 2013, p. 97.

Ibidem, pp. 110-111, 122.

Meyendorff 1989, pp.14-23.

Heather 2010, p. 587; Riasanovsky 1993, pp. 34-36; Maier 1986, pp. 165-166.

The Russian Primary Chronicle, 2013 p.137-138; Meyendorff 1989, pp. 22, 25-26; Simenova 2001, pp. 284-285. 
creó la regla para los monasterios estableciendo que los monjes debían cultivar y trabajar en talleres ya que la mera contemplación no era suficiente para testimoniar lafe ${ }^{27}$. Alcorrer del tiempo, los campesinos seavecindaron entornoalos monasterios y los monjes se convirtieron en misioneros, pero también en organizadores de la vida diaria del campesinado. Por tanto, el monacato oriental cumplió la función de propagar la fe entre la población rural y también llegaron a convertirse en centros de intercambio en muchos casos. Esa fue la función que empezaron a desempeñar en la Rus de Kiev aunque no se puede saber con certeza el impacto que sus enseñanzas tuvieron en el pueblo llano.

Para incrementar la identificación de los rus con la Iglesia bizantina, el príncipe Yaroslav, fomentó el culto a los primeros mártires de la iglesia de los eslavos del este, Boris y Gleb, quienes fueron asesinados por su hermano Svyatopolk durante la disputa de los 12 hijos de Vladimir por el poder. Se decía que Boris y Gleb se habían rehusado a atacar a Svyatopolk siguiendo las enseñanzas de Jesucristo. A la larga este sacrificio había beneficiado a Yaroslav, quien al final había vencido a Svyatopolk quedándose con el principado. La veneración a estos mártires no sólo les dio a los rus hombres santos de su pueblo sino que también fomentó entre la población la práctica cristiana de la humildad y el rechazo al uso de la violencia ${ }^{28}$. Me parece, que los mártires y los santos fueron también símbolos sagrados que nutrieron las prácticas religiosas y sociales de los rus y después de los rusos quienes heredaron esta memoria cultural como ocurre con el caso de Boris y Gleb o Vladimir el Grande.

Es necesario mencionar que la evangelización de los rus requirió de al menos una generación, ya que los propios clérigos no comprendían por completo la teología bizantina por lo cual tenían muchas deficiencias para comunicarla a los demás. De ahí que persistieran prácticas y creencias paganas combinadas con las cristianas ${ }^{29}$. La subordinación de la iglesia kievana a la bizantina explica el enorme impacto cultural de Bizancio entre los eslavos del este porque los referentes simbólicos, rituales y sagrados que adquirieron fueron los del cristianismo griego bizantino. Esta influencia a su vez dejó su impronta en la organización del Estado. Desde entonces, el estado ruso ha permanecido ligado a la iglesia cristiana oriental incluso durante el periodo soviético y ha sido uno de sus más férreos defensores.

\section{LA IGLESIA CRISTIANA DURANTE EL PERÍODO DE LA FRAGMENTACIÓN C. 1054-1328.}

Tras la muerte de Yaroslav el Sabio, sus hijos pelearon entre sí por el reparto de la herencia, la lucha resultó en la disgregación del principado de Kiev. Si bien las distintas parcialidades reconocían la preeminencia de Kiev y soñaban con apoderarse de su corona, otros principados adquirieron tanta o más importancia económica y política. Asimismo, existían principalidades en las que gobernaba una asamblea como fue el caso de Novgorod ${ }^{30}$. Cuando en siglo XI inició la decadencia de Kiev la cual dio lugar al periodo de fragmentación, la práctica del cristianismo bizantino fue un elemento de cohesión para los habitantes de todos aquellos territorios que alguna vez formaron parte de este Estado.

El cristianismo siguió afianzándose como un elemento de identidad entre los rus ya que, como señalé, construyó un pasado en el cual todos los eslavos del este tenían un origen común de acuerdo con la creencia en la creación divina. Lo demostraba que todos hablaban la misma lengua ${ }^{31}$. En 1051, San Antonio fundó el famoso Monasterio de las Cuevas en Kievsitio enelquellevabaalgunos años comoasceta. Izyaslav, hijo de Valdimir y príncipe de Polotsk, le otorgó los terrenos de una colina al monje quien poco después se retiró a vivir solo en una de las cuevas. Los monjes que se unieron a él labraron la iglesia y sus celdas en las cuevas de la colina. A San Antonio lo relevó como prior Barlaam y más tarde San Teodosio de Kiev. Según la hagiografía escrita por el monje Néstor, Teodosio desde niño se entregó a Dios, cuando oyó hablar de San Antonio se presentó ante él pidiéndole que lo consagrara monje. Nikón, uno de los tantos monjes del monasterio, fue el encargado de hacerle la tonsura, más tarde se le ordenó sacerdote. Como abad, Teodosio encabezó la construcción formal del monasterio y solicitó a los monjes cenobitas de Constantinopla la Regla de San Teodoro el Estudita misma que establecía que los monjes debían cultivar las virtudes de la castidad, la estabilidad y la caridad. San Teodosio impuso esta Regla en el monasterio de las Cuevas de Kiev. Por ello se le considera el fundador de los monasterios cenobitas en Rusia. Teodosio fomentó la caridad hacia los pobres, el trabajo de los monjes como si fuesen esclavos, de manera que exigía humildad y obediencia. Teodosio tuvo una vida de mortificaciones y de lucha por su fe, su madre hizo lo indecible por impedir que se entregara a la vida religiosa y no conforme con ese sufrimiento, todavía usaba cadenas para lacerar su cuerpo ${ }^{32}$. También intervino en la política, cuando los hermanos de Izyaslav, uno de los tres hijos de Yaroslav y su heredero principal, se levantaron en su contra, Teodosio le escribió una carta al príncipe Svyatoslav reprochándole haber asesinado a su hermano mayor, este no se atrevió a atacar al monje ${ }^{33}$. El Monasterio de Las Cuevas de Kiev fue el modelo que adoptaron los monasterios fundados posteriormente, y San Antonio y San Teodosio los modelos de los monjes, ascetas el primero y de los priores el segundo. Por tanto, podemos señalar a este monasterio como un lugar sagrado que demuestra la fe cristiana de los rus y sus descendientes, especialmente los rusos quienes siguen practicando el cristianismo ortodoxo sin influencias del catolicismo ni desviaciones.

En los siglos siguientes, los monasterios, casi siempre ubicados en los territorios fronterizos, fueron acumulando tierras de labor. Las recibían pordonaciones del príncipe y su séquito y por lo común las tierras de la iglesia eran trabajadas por quienes no tenían familia (izgoi) y quedaban bajo la protección del clero.

27. Baynes1996, p. 71.

28. Vernarsky 1969, p. 39; Meyendorff 1989, pp.19, 25; Boris y Gleb en http://orthodoxworld.ru/es/sviatye/2/index.htm recuperado 28 de noviembre de 2012; "The Martyrdom of Boris and Gleb" en Zenkovsky 1974, pp. 101-105.

Chulos 2009, p. 432.

Vernadsky 1976, pp. 83-98.

The Russian Primary Chronicle 2013, pp. 51-53

"The Life of St. Theodosious" en Kaiser y Marker 1994, pp. 67-71; Monje Néstor “Life of Our Blessed Father Theodosius, Abbot of the Crypt Monastery" en Zenkovsky1974, pp. 116- 134. 
Las disputas entre los príncipes de la Rus se complicaron más cuando la Orden de Livonia intentó convertir al cristianismo romano a los fineses delBáltico y la Orden Teutónica apareció en la costa delBáltico intentando colonizar la región. La Orden Teutónica tenía como objetivo convertir a los pueblos que habitaban a las orillas del Mar Báltico -y si era posible también a los eslavos del este- al cristianismo romano. Se establecieron en la costa y provocaron la migración de lituanos y letones hacia los principados de la Rus. Además, los polacos y los lituanos lucharon por extenderse al oriente a costa de las principalidades de la Rus. Estos embates implicaban la intención de los cristianos romanos por ganar adeptos entre los rus y sus vasallos, lo que atentaba contra una práctica cultural que los unía a pesar de las guerras intestinas, la religión bizantina. La Crónica de Novgorod ${ }^{34}$ trata, entre otros temas, sobre las disputas entre los gobernantes de las diferentes ciudades, asícomo de las correrías de los polovtsianos, los lituanos, los fineses y algunos eslavos occidentales quienes quemaban poblados y atacaban hasta a los niños y a los clérigos. De acuerdo con la crónica, la Rus padecía un gran desorden interno, lo cual no impedía que fundaran monasterios ${ }^{35}$. Esta actividad muestra que un referente para la identidad de los rus frente a sus enemigos era la religión, la cual formaba parte de su memoria cultural, asimismo edificaban lugares sagrados, los monasterios, donde los enemigos no entraban porque no eran miembros de la misma iglesia.

A partir del siglo XI los monjes también se ocuparon de relatar los sucesos que dieron origen al principado de Kiev y su disolución posterior. La literatura dejó de ocuparse exclusivamente de temas religiosos. Si bien los manuscritos más antiguos que se conservan datan del siglo XIII, las crónicas muestran que se apoyaron en escritos anteriores hoy perdidos. La redacción de las crónicas retoma el modelo bizantino y tiene como uno de sus objetivos proporcionarles a los rus un lugar en la historia de la salvación cristiana pero con base en la iglesia oriental. De cualquier forma, recogieron tradiciones orales que relataban la historia de los eslavos tal como ellos la concebían. Las crónicas más antiguas, como las que utilizo, inician la narración de la historia de los eslavos del esteen elmomento en que los administradores del imperio bizantino mencionaron por primera vez a los rus, es decir, en el siglo $I X^{36}$. Una vez más, los monjes fijaron por escrito esa memoria cultural que empezó a modificarse cuando los eslavos del este adoptaron la fe bizantina, las crónicas fueron nuevos monumentos para alimentarla.

En cada principalidad adoraban sus propias advocaciones de la virgen o bien a sus santos locales, pero las creencias y los ritos litúrgicos practicados y propagados por la Iglesia bizantina propiciaban una cierta unidad religiosa. Por ejemplo, en Novgorod se veneraba el icono de Nuestra Señora de los Pecados ubicada en la Iglesia de Santiago. En el sigloXIII este icono fue trasladado a la Iglesia de EI Salvadory empezó ahonrarse como la protectora en la victoria de Novgorod en febrero de 1170. La catedral de Santa Sofía en esa misma ciudad era considerada como su símbolo novgorodiano. El fervor de los novgorodianos y su poderpolítico fuerontalesqueen 1156instalaronsupropioarzobispado. Pero no fueron los únicos, la difusión del cristianismo entre los rus había dado lugar a que en el siglo XIII existieran 16 diócesis ${ }^{37}$. Así pues, los objetos del culto podían cambiar pero lo importante era la fe en que vírgenes y santos velaban y protegían a los rus.

Asimismo, las prácticas bizantinas continuaron arraigando en los principados deloseslavos deleste. Para empezar, lasimágenes religiosas siguieron los patrones bizantinos pues los primeros artesanos llegaron de Bizancio y con ellos algunos abjasios ${ }^{38}$; pronto una escuela de pintura de iconos y de manufactura de mosaicos se desarrolló en las tierras de la Rus. Asimismo, la arquitectura en piedra, casi toda enfocada en levantar templos, adoptó los cánones bizantinos. Andrey Bogoliubskii, príncipe de Vladimir-Suzdal y Kiev, procuró ejercer el poder sobre sus dominios imitando a los emperadores bizantinos. Otra práctica que la dinastía de Vladimir- Suzdal tomó de Bizancio consistió en invocar a santos militares paraque los protegieran en las batallas. Los príncipes erigieron iglesias en las que representaban a santos como Demetrio o Teodoro, militares romanos originarios del oriente del imperio que murieron por practicar el cristianismo y fueron considerados mártires. Los príncipes de Valdimir-Suzdal incluso le atribuyeron a Boris y Gleb calidad de santos militares ${ }^{39}$, apesardequesu santidad se debía aque se negaron a pelear en contra de su hermano. Esta práctica iniciada en Vladimir-Suzdal respondió, me parece, a la guerra constante que vivían los rus. Estas adquisiciones culturales se sumaron a las prácticas ancestrales eslavas, las bylinas son una muestra de ello, las cuales con el paso de los años incluyeron algunos elementos cristianos ${ }^{40}$.

Cuando los mongoles subyugaron gran parte de los principados de la Rus en la Crónica de Novgorod se señala que la conquista mongola fue un castigo divino por los pecados cometidos por los rus. Es claro que el o los redactores tuvieron que proporcionar una explicación que justificara la victoria de los paganos. En el Relato sobre la destrucción de Riazan ${ }^{41}$ también se atribuye la victoria de Batú a los pecados cometidos por los rus. Según esta fuente, el príncipe Yury Ingvarevich solicitó primero la ayuda del Gran Príncipe de Vladimir quien no se la brindó porque decidió enfrentar a los mongoles solo con sus fuerzas.

Por tanto, ningún príncipe de la Rus apoyó a Riazan cuando el ataque erayainminente. Yuryenvió asu hijoFedorcon regalosanteBatú, pero éste exigía que les entregaran a todas las mujeres nobles. El embajador deRiazancontestó que los cristianos no entregaban sus mujeresalos paganos. Esto le costó la vida. El autor anónimo describe cómo los mongoles invadieron el principado y descuartizaron a todas las familias boyardas, a los monjes y a la población en general y quemaron la ciudad. Tan solo se salvó el hermano de príncipe Yury, Ingvar Ingvarevich quien estaba en Chernigov cuando ocurrió la matanza y, más tarde, reconstruyó la ciudad de Riazan. Este fue el inicio del dominio del janato Kipchak sobre gran parte de los principados rusos.

"Mediaval Sourcebook: Privileges Granted to German Merchants Novgorod, 1229" 1998, pp. 1-3.

Vernadsky 1969, pp. 41-43, 51; Riasanovsky 1993, pp. 39- 54.

Verona 2007, pp. 93-109.

Lenhoff 2004, p. 400; Riasanovsky 1993, pp. 54, 79; The Chronicle of Novgorod 1016-1417 1914, p. XI.

Monje Néstor, "Bishop Simon: The Coming of the Greek Iconographers from Constantinople to Abbot Nikon" en Zenkovsky 1974, pp. 138-140.

White 2004, pp. 493-513.

Longworth 2005, p. 44; Dukes 1990, pp. 24-25; Riasanovsky 1993, pp. 58-59; Moss 2005, pp.47-52. 
Los mongoles kipchak no obstaculizaron la creación de monasterios, se fundaron un gran número como una reacción a la invasión. En efecto, la Iglesia de la Rus, que en el proceso de la dominación kipchak se transformó en rusa ${ }^{42}$, facilitó mantener una cultura diferente a la de los mongoles al mismo tiempo que reforzó el poder de los príncipes. Hay que recordar que la base de las prácticas culturales cristianas estaba en la liturgia, los monjes alentaron las peregrinaciones a Tierra Santa lo que mantuvo a los rusos en relación con otros cristianos orientales. Los príncipes siempre iban acompañados por prelados cristianos para presentar sus respetos al jan. Además, los clérigos hacían las veces de mediadores entre la nobleza. Los clérigos más cercanos al pueblo ignoraban la teología, de manera que los campesinos observaban la liturgia, pero sus cantos no se ajustaban por completo a ella porque no recibían la instrucción necesaria, así que mantuvieron formas tradicionales de canto, lo que no impidió que se consideraron cristianos orientales.

Ya que muchos eslavos huyeron al noreste, los monasterios ayudaron a organizar el espacio y a ordenar la colonización de la región. Los monjes conseguían permiso de los señores para establecerse en las fronteras, reclutaban colonos y se dedicaban a la explotación sistemática de los bosques consolidando su dominio territorial. Los campesinos conservaban su libertad de movimiento, aunque debían pagar rentas a los monjes. Ya que estas instituciones y sus miembros se dedicaban a honrar a Dios estaban exentos de pagar yasak, como se denominaba el tributo que los príncipes debían abonar a los mongoles. Para estos, a pesar de su condición de terratenientes, los monjes no debían pagar tributo porque eran hombres dedicados a practicar una de las religiones de El Libro que los musulmanes respetaban. De hecho, en la capital del janato de Kipchak residía un obispo bizantino quien junto con el metropolitano de todas las Rusias propiciaron un acercamiento entre el emperador bizantino Miguel VIII Paleólogo y el jan. Por tanto, las relaciones cordiales entre ambos protegieron a la iglesia rusa que acataba las disposiciones y acuerdos del clero bizantino con los mongoles ya que el metropolitano todavía dependía del patriarcado de Constantinopla ${ }^{43}$.

Por ejemplo, alrededor de 1313 el jan Uzbek otorgó al metropolitano Pedro inmunidad sobre todas sus posesiones. Ordenó que nadie le confiscara sus bienes muebles ni inmuebles, no se le exigiera tributo ni a él ni a su gente porque, decía, los negocios del metropolitano eran negocios de Dios. Ninguno de los habitantes de sus propiedades debía ir a la guerra, el único compromiso del metropolitano era rogar a Dios por la victoria de los mongoles. Enfatizaba que cualquiera que violara la propiedad de la iglesia estaba violando los intereses divinos ${ }^{44}$. Los monasterios fueron incluidos en esta protección. Como es evidente, las religiones son ideologías que, como destacó Althusser, regulan las relaciones de dominación y las presenta como voluntad divina ${ }^{45}$. La relación de dominación era de los mongoles a los rusos y de la nobleza rusa, incluido el clero, a los campesinos.

EnelsigloXVIlosmonasterios seguían la regla establecida por Sergio deRodoney, portanto, seapegabanal funcionamiento delmonasterio de La Trinidad/San Sergio ${ }^{46}$. El apoyo a los monasterios muestra la política de tolerancia que los mongoles tuvieron hacia muchas prácticas culturales de los eslavos sometidos; mientras la Iglesia bizantina contribuyera a mantener la paz, ellos no intentaron convertir a sus fieles ni apoderarse de su riqueza. Gracias a este principio de tolerancia, los príncipes rusos conservaron un rasgo cultural adquirido desde la Rus de Kiev: el cristianismo bizantino el cual contribuyó definitivamente a que los rus, más tarde rusos, conservaran una identidad diferente a la de sus conquistadores.

\section{CONCLUSIÓN}

Como he analizado en este artículo, la Iglesia bizantina griega, fue un factor que contribuyó a que los eslavos del este construyeran una memoria culturalqueles permitió identificarse como miembros de una mismacomunidadcon unahistoria compartida yelementos culturales casi homogéneos que los mantuvieron unidos desde que ésta fue adoptada por el príncipe de Kiev. La Iglesia bizantina proporcionó a los rus una concepción simbólica de su pasado y de su entorno y unas creencias que, junto con la lengua, les brindó la posibilidad de mantener una identidad común a pesar de las disputas políticas entre ellos, de los intentos de sus vecinos por someterlos y de la conquista de los mongoles. La unión religiosa y la existencia de una iglesia consolidada, le ofreció al primer estado ruso la oportunidad de adoptar costumbres tanto enelejercicio del podercomo en la vidacotidianaquecontinuaron presentes en la historia posterior de los rus y más tarde de los rusos. La religión como un rasgo cultural importante en la identidad de los pueblos ha proporcionado, como muestra este artículo, un rasgo de identidad a los rusos que ha persistido hasta la actualidad.

42. Durante el dominio mongol los rus se diferenciaron entre sí. Aquellos que formaron parte del janato kipchak empezaron a denominarse rusos. Ortega 2014, pp. 145-146.

43. Meyendorff 1989, pp.45-46, 70-72.

44. "Mongol Immunity Charter (larlyk) to Metropolitan Peter (ca. 1313)" en Kaiser y Marker 1994, pp.101-102.

45. Althusser 1997, p. 55

46. Vernadsky 1969, p.66; Longworth 2005, pp. 49-50; Maier 1986, p.167; Riasanovsky 1993, pp. 118-119, 121; Dukes 1990, pp. 38-40; Lenhoff 2004, 


\section{BIBLIOGRAFÍA}

- Althusser, Louis, La filosofía como arma de la revolución. México, Siglo veintiuno editores, 1997.

- Assmann, Jan. "Collective Memory and Cultural Identity" en New German Critique, no. 65, Cultural History, Cultural Studies (1995) pp. 125-133 en http://www.jstor.org/stable/488538 recuperado 21 de junio de 2020.

- Baynes, Norman H., El imperio bizantino. México, Fondo de Cultura Económica, 1996.

- Boris y Gleb en http://orthodoxworld.ru/es/sviatye/2/index.htm recuperado 28 de noviembre de2012.

- Bushkovitch, Paul, Historia de Rusia. Madrid, Akal, 2013.

- Chulos, Chris J., reseña del libro "Popular Religion in Russia: 'Double Belief' and the Making of an Academic Myth” por Stella Rock en Slavic Review, 68:2, (2009) pp. 431-432 en http://www,jstor.org/stable/27697990, recuperado 1 de noviembre de 2012.

- Dukes, Paul, A History of Russia. Medieval, Modern, Contemporary. [Hong Kong], MacMillan, 1990.

- Eusebio de Cesárea, Historia eclesiástica. La formación de la iglesia desde e/siglo I hasta el siglo III. Trad. directa del griego George Grayling. Barcelona, Edit. Clie, 2008.

- Heather, Peter, Emperadores y bárbaros. El primer milenio de la historia de Europa. Barcelona, Critica, 2010.

- Historia Universal 7. El origen de las grandes religiones. Lima, Salvat Editores, 2005.

- Hussey, J. M., "VI. La ciudadela cristiana. El mundo bizantino de los siglos IX al X” en David Tablot Rice, (dir.), Historia de las civilizaciones 5. La Alta Edad Media. Hacia la formación de Europa. México, Alianza Editorial/Edit. Labor, 1989, pp. 176-210.

- Kaiser, Daniel H. y Gary Marker (comps.), Reinterpreting Russian History. Readings, 860-1860s. New York, Oxford, Oxford University Press, 1994.

- Lenhoff, Gail reseña del libro "Autour du mythe de la Sainte Russie: Christianisme, pouvoir et société chez les slaves orientaux (XeXVlle siècles)" de Vladimir Vodoff en Slavic Review, 63:2, (2004) pp. 399-400 en http://www.jstor.org/stable/3185753, recuperado 2 de noviembre de 2012.

- Longworth, Philip, Russia. The Once and Future Empire from Pre-history to Putin. Nueva York, St. Martin's Press, 2005.

- Lorenzen, David N. y Benjamín Preciado, Ataduray liberación. Las religiones de la India. México, El Colegio de México, Centro de Estudios de Asia y África, [2003].

- Maier, Franz Goerg, Las transformaciones del mundo mediterráneo del siglo III / VIII. México, Siglo XXI, 1986.

Mediaval Sourcebook: Privileges Granted to German Merchants Novgorod, 1229, selección de Paul Halsall, octubre de 1998 tomado de G. F.Sartorius, ed. Urkundliche Geschichte des Deutschen Hanse.J. Lappenberg, rev., (Hamburgo, 1830), vol. II, p. 29; reimpreso en Roy C. Cave y Herbert H. C. eds., A Source Book of Medieval Economic History, (Milwaukee; The Bruce Publishing Co., New York: Biblio and Tannen, 1965), pp. 225-231 en http://www.fordham.edu/Halsall/source/1229novgorod-germans.asp recuperado 15 de noviembre de 2012, pp. 1-3

- Meyendorff, John, Byzantium and the Rise of Russia. A Study of Byzantino-Russian Relations in the Forteenth Century. New York, ST. Vladimir's Seminary Press, 1989

- Mircea, Eliade, Historia de las creencias y las ideas religiosas I. De la Edad de Piedra a los misterios de Eleuisis. Vol. I, Barcelona, Paidós, 1999.

- Mol, Hans, Identity and the Sacred: A Sketch for a New Social-Scientific Theory of Religion. Oxford, Blackwell, 1976.

- Moss, Walter G., A History of Russia. Vol l: to 1917. Londres, Anthem Press, 2005.

- Ortega Soto, Martha, "Orígenes de los conflictos nacionales en Europa del este" en Martha Ortega Soto, José Carlos Castañeda Reyes y Federico Lazarín Miranda (coords.), Jan Patula constructor de la historia del presente. Memoria del l y IISeminarios en Homenaje al Maestro Jan Patula Dobek. Londres, UAM-I, Plaza y Valdés, México, 2003, pp.117-129 
- Ortega Soto, Martha, Origen de un imperio: cómo el estado ruso llegó a la cuenca del Pacífico. Tesis de Doctorado en HumanidadesHistoria, México, Departamento de Filosofía, División de Ciencias Sociales y Humanidades (DSCH) Universidad Autónoma Metropolitana, unidad Iztapalapa, noviembre de 2014.

- Ortega, Martha, "Violencia intrínseca: la historia de los eslavos del sur” en Martha Ortega Soto, José Carlos Castañeda Reyes y Federico Lazarín Miranda (comps.), Violencia: estado y sociedad, una perspectiva histórica. México, UAM-I, Cámara de Diputados LIX Legislatura, Miguel Ángel Porrúa, 2004, pp.151-199.

- Pohl, Walter, "Conceptions of Ethnicity in Early Medieval Studies" en Lester K. Little y Barbara H. Rosenwein, Debating the Middle Ages: Issues and Readings, [s. I.], Blackwell Publishers, 1998, pp. 13-24 en http://www.kroraina.com/bulgar/pohl_etnoicity.html recuperado16 de septiembre de 2011

- Riasanovsky, Nicholas V., A History of Russia. Nueva York, Oxford University Press, Oxford, 1993.

- Serrano del Pozo, Joaquín, "El emperador Heraclio (610-641) entre la historia y la leyenda:un estado de la cuestión" en INTUS-LEGERE HISTORIA, vol. 12, no. 1, (2018) pp. 87-113 en Dialnet-EIEmperadorHeraclio610641EnteLaHistoriaYLaLeyenda-6589081.pdf recuperado 15 de mayo de 2020.

- Simenova, Liliana. reseña del libro de FrancisJ. Thompson, “The Reception ofByzantine Culture in Medieval Russia” en Russian Review, 60:2, (2001) pp. 284-285 en http://www.jstor.org/stale/2679552 recuperado 1 de noviembre de 2012.

- Tamara Talbot Rice, "VII. Crisol de pueblos. La Europa oriental y el apogeo de los eslavos" en David Talbot Rice, (dir.), Historia de las civilizaciones 5. La Alta Edad Media. Hacia la formación de Europa. México, Alianza Editorial/Edit. Labor, 1989, pp.211-242.

- The Chronicle of Novgorod 1016-1417. Trad. Del ruso de Robert Michell y Nevill Forbes (1883-1929). Introd. Raymond Beazby en http:// faculty.washington.edu/dwaugh/rus/texts/MF1914.pdf recuperada 28 noviembre de 2012

- The Russian Primary Chronicle. Laurentian Text. Ed. Y trad. Samuel Hazzard Cross y Olgerde P. Sherbowitz-Wetzor. The Medieval Academy of America, Cambridge, Massachusetts, [2013].

- Vernadsky, George, A History of Russia. New Haven, Yale University Press, 1969.

Vernadsky, George, Kievan Russia. New Haven y London, Yale University Press, 1976.

- Verona Codeso, Patricia, "Las crónicas griegas y la entrada de los rusos en la Historia" en Minerva. Revista de Filología Clásica, 20 (2007), pp. 93-109 en https://dialnet_unirioja.es/servlet/articulo?codigo=2390996 recuperado 3 de marzo de 2017.

- White, Monica. “A Byzantine Tradition Transformed: Military Saints under the House of Suzdal”" en Russian Review, 63:3, (2004) pp. 493-513 en http://www.jstor.org/stable/3664652 recuperado 9 noviembre de 2012.

- Zenkovsky, Serge A. (ed., trad., introd.), Medieval Russia's Epics, Chronicles and Tales. Estados Unidos, A Meredian Book, [1974]. 